\title{
Acute Stent Loss and Its Retrieval of a Long, Tapering Morph Stent in a Tortuous, Calcified Lesion
}

\author{
Santosh Kumar Sinha ${ }^{\mathrm{a}, \mathrm{b}}$, Anupam Mahrotra ${ }^{\mathrm{a}}$, Nishant Kumar Abhishekh ${ }^{\mathrm{a}}$, Mahmodula Razi $^{\mathrm{a}}$, \\ Puneet Aggarwal $^{\mathrm{a}}$, Sunil Tripathi ${ }^{\mathrm{a}}$, Lokendra Rekwaal ${ }^{\mathrm{a}}$, Anupam Singh ${ }^{\mathrm{a}}$
}

\begin{abstract}
A 72-year-old male with diabetes and smoking as coronary risk factors was evaluated for chronic stable angina - Canadian Cardiovascular Society III - despite guideline directed medical treatment which revealed a diffuse, tortuous, calcified narrowing (90\% stenosis) in left circumflex (LCx) coronary artery. After predilatation, a $3.0-2.5 \times 60 \mathrm{~mm}$ BioMime Morph stent - long tapering stent (Sirolimus eluting stent, Meril life Sciences, India) - was tracked which failed and dislodged to right deep femoral artery during its pullback. It was successfully retrieved by EN snare: 6 - $10 \mathrm{~mm}$ (Merit Medical, USA) by contralateral femoral approach. Lesion was further dilated and successfully stented with another $3.0-2.5$ $\times 60 \mathrm{~mm}$ BioMime Morph stent at $10 \mathrm{~atm}$ pressure showing proper stents expansion with TIMI-3 coronary flow. Our case highlights trackibility issues and importance of adequate lesion preparation before stent deployment in a tortuous and calcified vessel especially with very long stent. To the best of our knowledge, this is the first such case report demonstrating dislodgement and successful retrieval of long, tapered Morph stent.
\end{abstract}

Keywords: Calcium; Chronic stable angina; Stent dislodgement; Tapered stent; Morph stent; EN snare

\section{Introduction}

Implantation of stent has significantly reduced restenosis and the need for repeat intervention after percutaneous coronary intervention (PCI). Stent dislodgement is an uncommon occurrence in modern PCI and is often associated with significant morbidity in form of coronary thrombosis and subsequent myocardial infarction, sudden cardiac death, and acute limb occlusion [1-4]. In the past, manual crimping of stents

Manuscript submitted November 4, 2017, accepted November 15, 2017

aDepartment of Cardiology, LPS Institute of Cardiology, G.S.V.M. Medical College, Kanpur, Uttar Pradesh, India

${ }^{\text {b} C o r r e s p o n d i n g ~ A u t h o r: ~ S a n t o s h ~ K u m a r ~ S i n h a, ~ D e p a r t m e n t ~ o f ~ C a r d i o l-~}$ ogy, LPS Institute of Cardiology, G.S.V.M. Medical College, Kanpur, Uttar Pradesh 208002, India. Email: fionasan@rediffmail.com

doi: https://doi.org/10.14740/cr627w which is rarely practiced now was associated with a significantly increased risk of stent dislodgement and embolization. Even then, the problem of stent embolization has not completely been eliminated especially when negotiating tortuous and/or calcified arteries and passage through a previous stent [5].

\section{Case Report}

A 72-year-old male with diabetes and smoking as coronary risk factors was evaluated for chronic stable angina - Canadian Cardiovascular Society III - despite guideline directed medical treatment which revealed a diffuse, tortuous, calcified narrowing (90\% stenosis) left circumflex ( $\mathrm{LCx}$ ) coronary artery. Electrocardiogram was normal and echocardiogram revealed mild concentric left ventricular hypertrophy with normal ejection fraction. The coronary angiography through right transfemoral approach showed a diffuse, tortuous, calcified narrowing (90\% stenosis) in LCx coronary artery (Fig. 1a, b). Percutaneous transluminal coronary angioplasty (PTCA) of LCx was planned after proper consent. Left main artery was hooked with a 6-F extra backup (EBU-3.5) guiding catheter (Medtronic, USA) and a 0.014" runthrough wire was parked in terminal obtuse marginal branch (OM) of LCx. There was a feel of calcium while parking the wire. Lesion was sequentially predilated with $1.5 \times 10,2 \times 10$ and $2.5 \times$ $10 \mathrm{~mm}$ Quantum Maverick semicompliant balloons (Boston Scientific, USA) at 10 - 15 atm pressure (Fig. 2a, b). A $3 \times 60$ $\mathrm{mm}$ long, tapered Morph stent (Sirolimus eluting stent, Meril Life Sciences, India) was tracked across the lesion (Fig. 3a), but it failed to cross the lesion because of tortuosity and underlying calcium. Stent was withdrawn and while pulling it back, guiding backed out due to non-co-axial engagement and wire came out of the LCx. When checked, only balloon of the stent came out of the guiding catheter and dislodged, and embolized stent was visible in right common femoral artery (Fig. 3b). After few seconds, it moved further down to deep femoral artery (Fig. 4a, b). Contralateral femoral artery was accessed with $7-\mathrm{F}$ sheath. Judkins right (JR) guiding catheter was carefully parked in right deep femoral artery over the terumo wire (Terumo Inc., Japan) (Fig. 4b, c). Guiding catheter was further pushed down near to the embolized stent (Fig. 5a). Wire was withdrawn and $6-10 \mathrm{~mm}$ EN snare (Merit Medical, USA) was pushed through the JR catheter and opened at its tip to catch the stent (Fig. 5b). Once caught, 


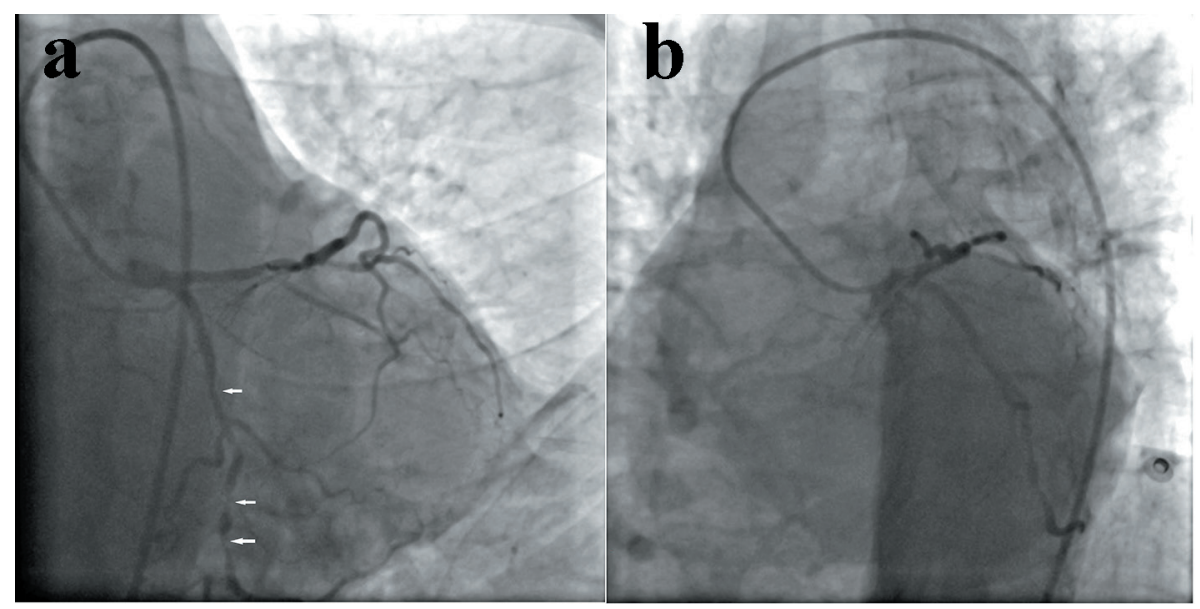

Figure 1. Angiogram showing diffuse, tortuous, calcified narrowing (90\% stenosis) in left circumflex (LCx) coronary artery (a: AP caudal view; b: LAO caudal view).

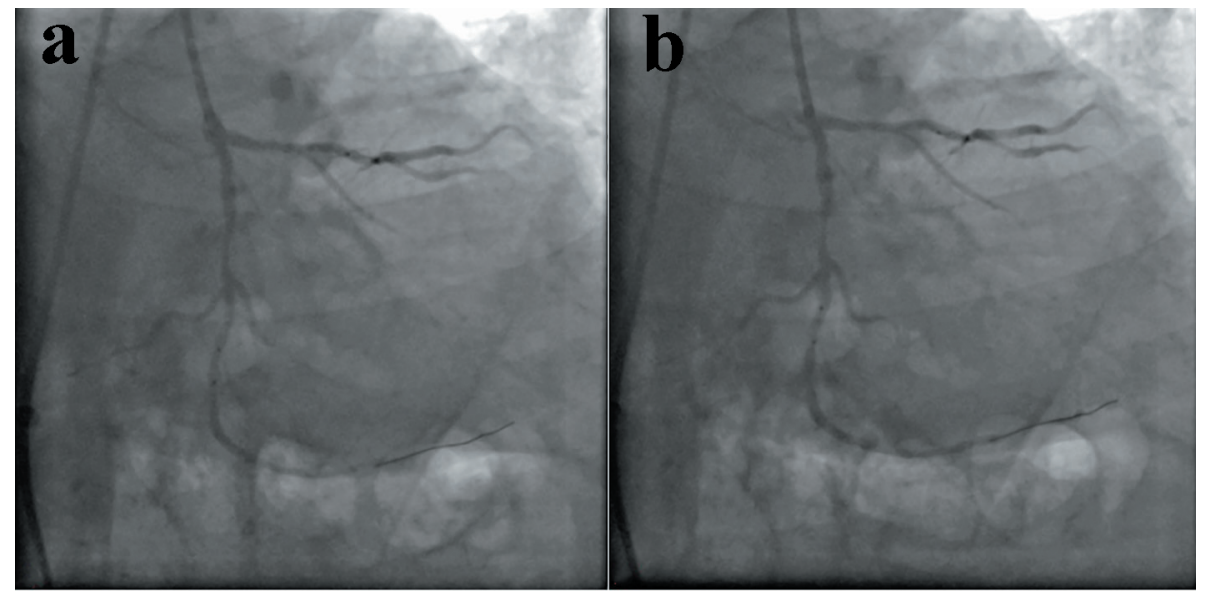

Figure 2. Lesion was sequentially predilated with multiple balloon at 10 - 15 atm pressure (a, b).

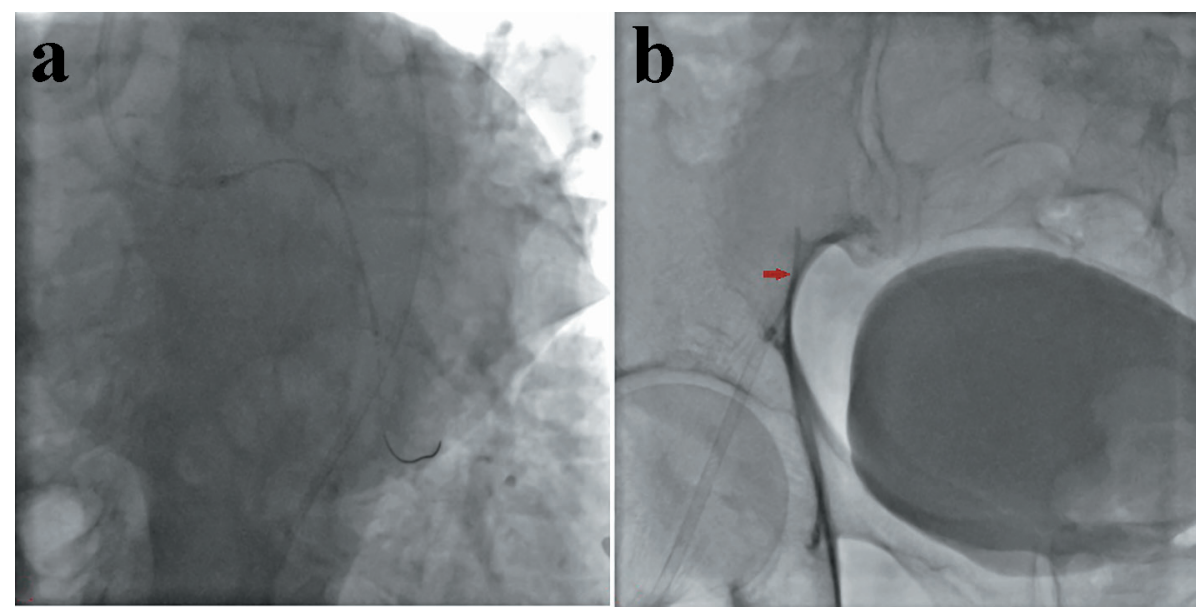

Figure 3. Morph stent failed to cross the lesion leading to backing of guide catheter (a). Embolized stent visible in right common femoral artery (b). 


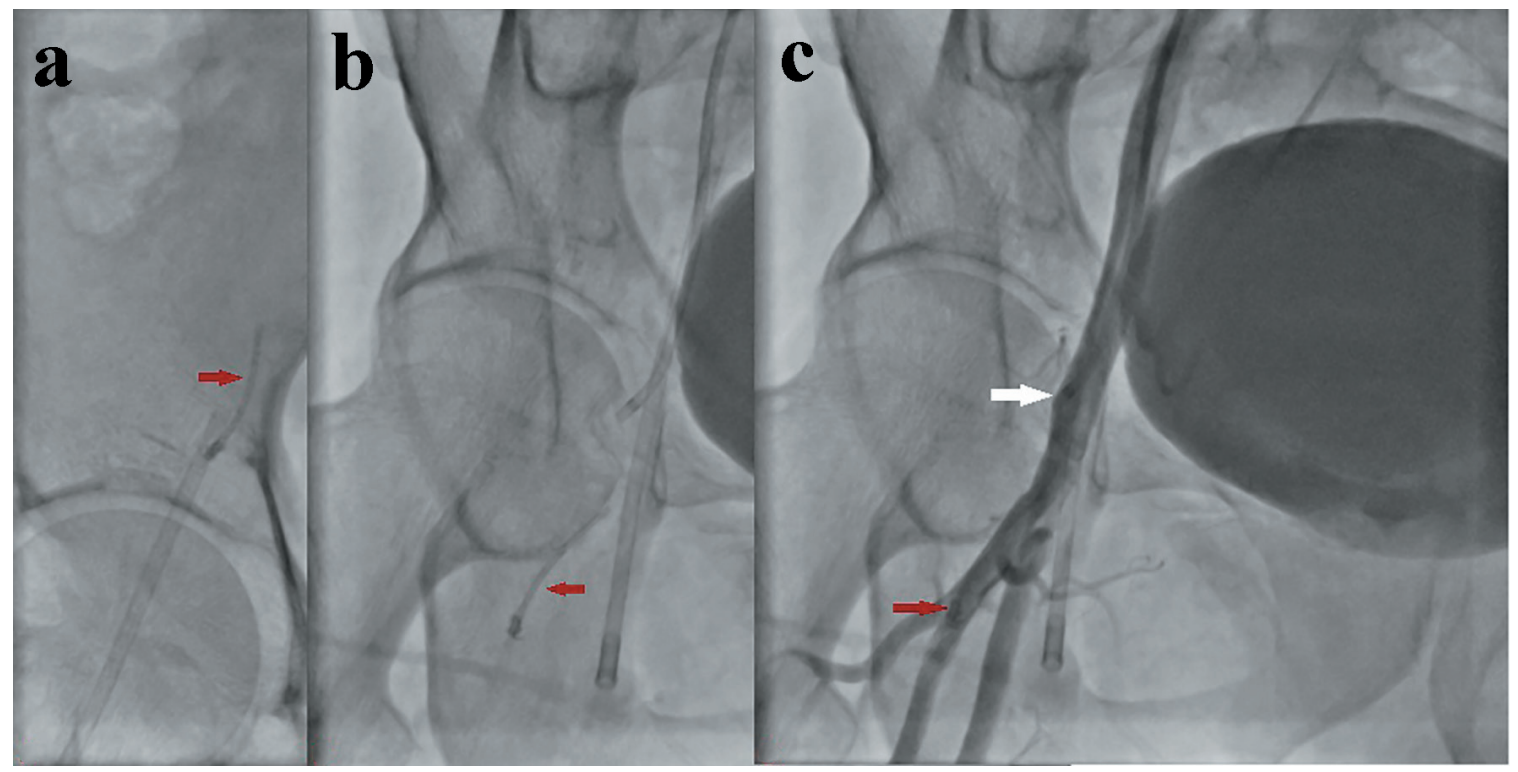

Figure 4. Embolized stent further moving down to deep femoral artery $(a, b)$. Judkins right (JR) guiding catheter was carefully parked in right deep femoral artery $(b, c)$.

snare was pulled and guiding catheter was pushed to firmly trap the stent leaving no space behind and whole assembly: stent-snare-guiding catheter was pulled back under fluro surveillance (Figs. 5c, d and 6a, b). Sheath was firmly held with left hand and whole assembly was successfully pulled out (Figs. 6c, d and 7a, b). LCx was again hooked and lesion was aggressively prepared by $2.75 \times 10$ and $3 \times 10 \mathrm{~mm}$ Quantum Maverick non-compliant balloons at 18 atm pressure. It was successfully stented with $3 \times 60 \mathrm{~mm}$ Morph stent at $10 \mathrm{~atm}$ pressure and further post dilated with $3.5 \times 10 \mathrm{~mm}$ Quantum Maverick non-compliant balloon at 15 atm pressure achieving TIMI-3 flow (Fig. 8a, b, c). His hospital stay remained uneventful and was discharged with aspirin $150 \mathrm{mg}$, clopidogrel $150 \mathrm{mg}$, rosuvastatin $20 \mathrm{mg}$, metoprolol $100 \mathrm{mg}$, ram- ipril $10 \mathrm{mg}$ and glibenclamide $1 \mathrm{mg}$ daily.

\section{Discussion}

As currently used stents come with premounted systems, the risk of stent embolization has been drastically cut down with incidence of $0.32-8.4 \%$ [2]. It can be secondary to marked coronary angulation, unfavorable anatomy, coronary calcification, underestimation of stent size, inadequate coronary predilatation, and direct stent. Stent dislodgement from the delivery system most often occurs when the stent balloon assembly is pulled back into the guiding catheter [6]. In our case, calcification was the hurdle in preparing the vessel for stenting. Despite
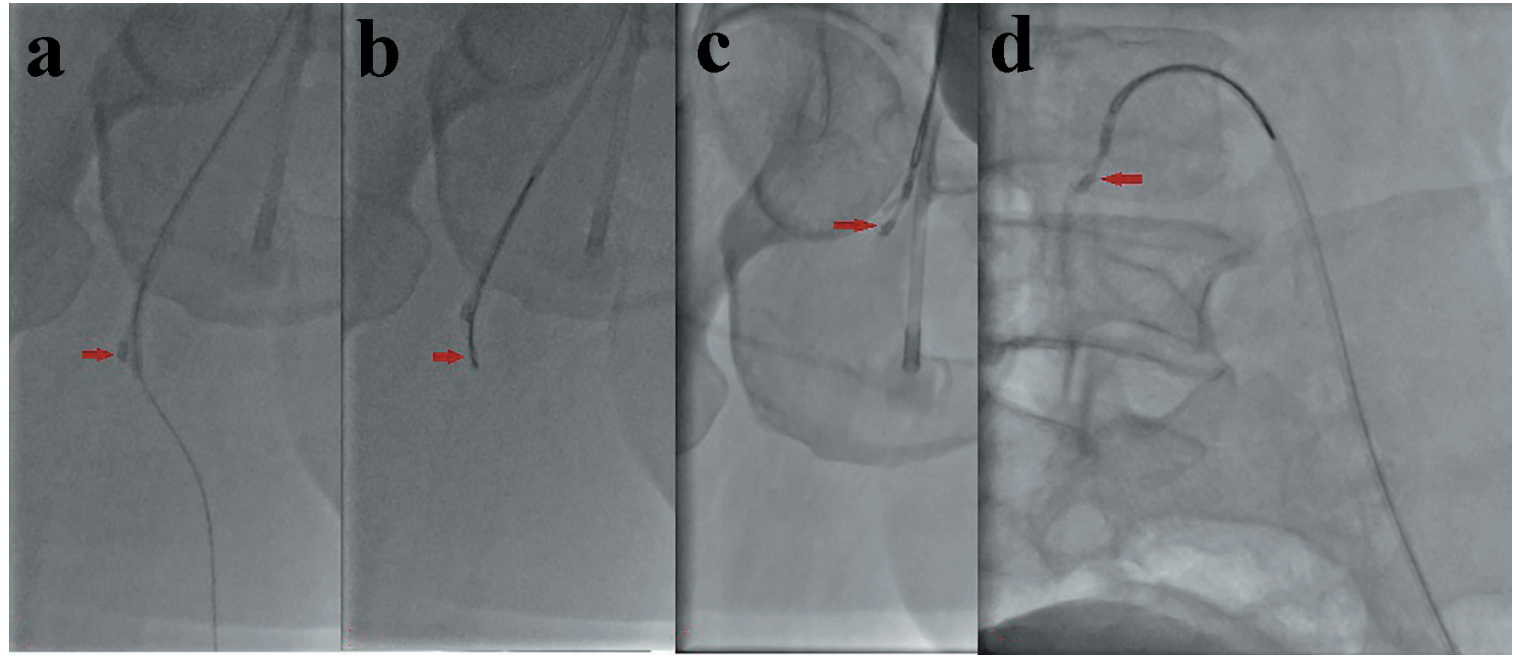

Figure 5. Embolized stent being trapped and retrieved $(a, b)$. Whole assembly: stent-snare-guiding catheter was pulled back under fluoroscopic surveillance (c, d). 


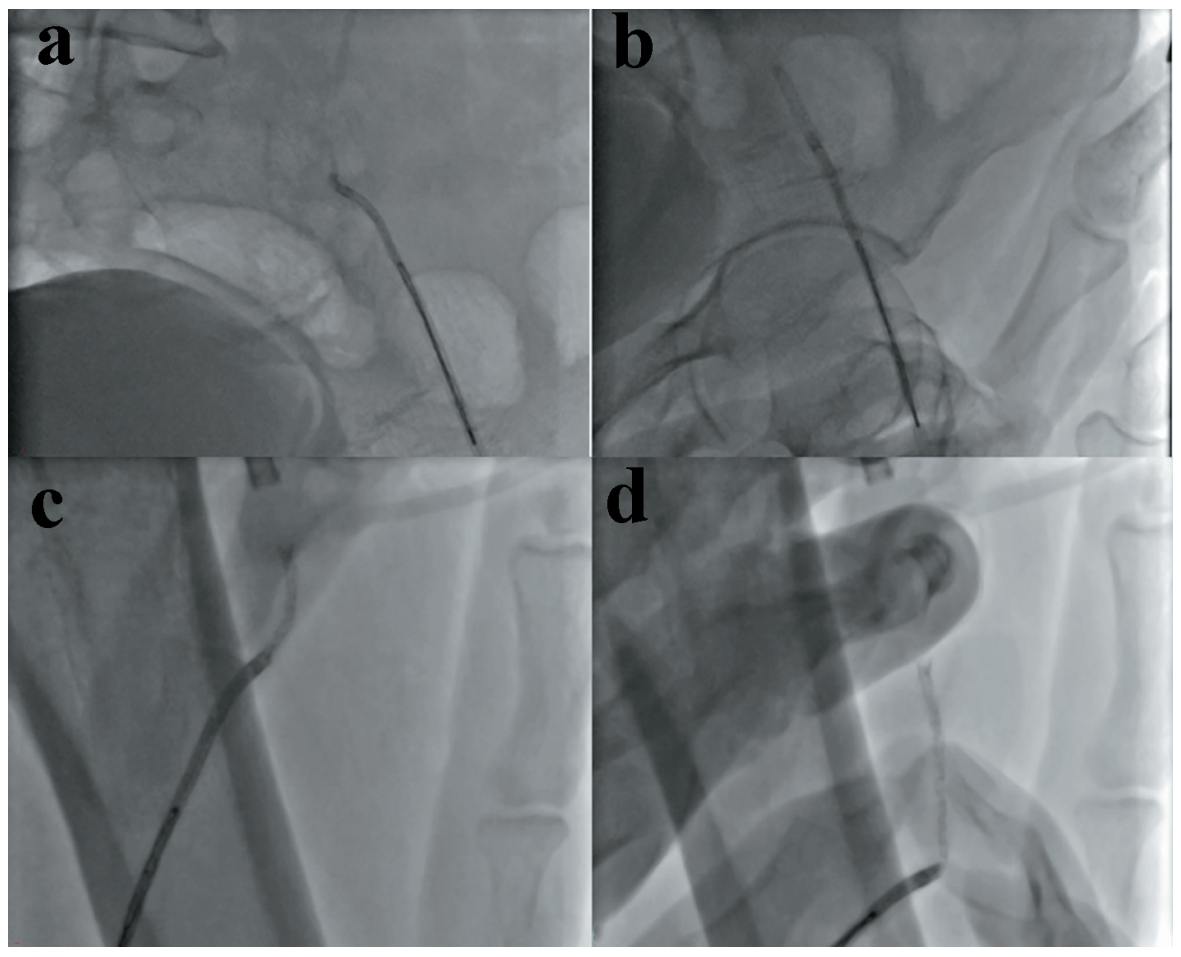

Figure 6. Sheath was firmly holded with left hand and whole assembly was successfully pulled out (a, c, c, and d).

graduated predilatation with multiple balloons, the vessel was still unprepared for stenting. Secondly, stent was forcefully placed but as it was tortuous, it did not allow. Third, stent was very long $(60 \mathrm{~mm})$ which always has the potential for dislodgement. Instead of this, vessel should have been prepared bigger size balloon. Sometimes, plaque modification should have been done by rota ablation, scoring balloon, or cutting balloon. In our case, lesion was redilated at relatively high balloon pressure to obtain sufficient dilation speaks about its hardness because of underlying calcium. Therefore, stenting of the poorly prepared artery should be avoided. Fortunately, the stent was not dislodged around the coronary system and as soon as we observed the demounted stent in the femoral artery, it was retrieved.

Different other percutaneous retrieval techniques have also been described to retrieve embolized stents from the coronary and the peripheral circulation, including low-profile angioplasty balloon catheters, gooseneck snares, myocardial biopsy forceps, and multipurpose baskets. In our patient, the guiding catheter and all the PCI system came off because we had to push the stent hard into the tough lesion, and in the end the dislodged stent migrated to common femoral artery. In this case, it might also be more suitable and useful to catch the floating end of the stent than a simple loop, and the retrieval technique itself was easy. Advantage with EN snare is its availability in different sizes and as it has three interlacing loops which give it a unique shape when it opens, making it perfect to grasp the embolized stent (Fig. 7b).

In the present scenario to treat lesions $>48 \mathrm{~mm}$, one is compelled to use two or more stents. Implantation of multiple overlapping stents makes the vessel rigid due to excess metal, fracture due to rigidity, restenosis because of higher vascular injury, polymer inflammation, delayed healing, aneurysm because of excessive drug dose, and contrast overload. Further, it has been demonstrated that overlapping stents are associated with impaired angiographic and long-term clinical outcome, including death or myocardial infarction [7]. Another important factor to be considered is anatomical mismatch between currently available cylindrical stents with natural taper of coronary arteries with higher distal diameter and has a propensity to cause distal vessel dissection.

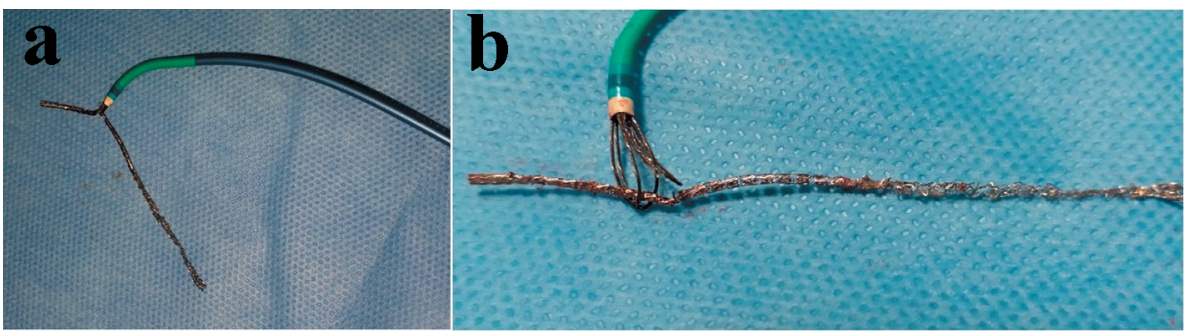

Figure 7. Retrieved stent snared by EN snare $(a, b)$. 


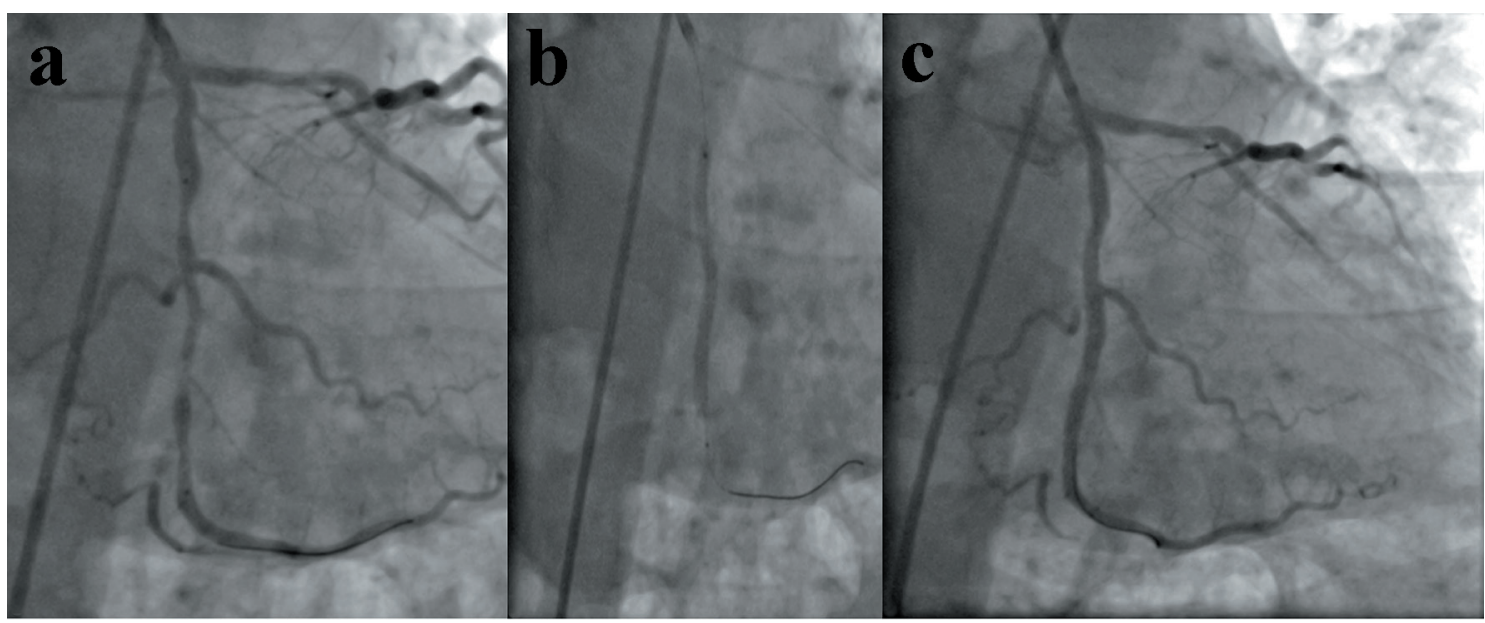

Figure 8. Rewiring of LCx and successful stenting with $3-2.5 \times 60 \mathrm{~mm}$ Morph stent following aggressive predilatation by bigger balloon (a, b, c).

Stent size mismatch has been identified as an important factor for restenosis in some patient particularly where vessel diameter changes to a significant degree over the length of a stent [8]. These are commonly encountered due to tapering of coronary vessels. In such cases, clinicians have to decide the stent sizing carefully as a large diameter mismatch may lead to excessive damage in the vessel wall and may increase the risk for clinical failure [9]. Since conventional stents may not be able to adapt effectively in tapered vessels, appropriate stent sizing becomes challenging [10]. In this regard, tapered stents have been developed recently to minimize clinical failure and maximize the clinical benefits in such patients. We consider that, using a tapered stent has advantages of excellent adaptation to vessel tapering and good apposition. In cases involving stenosis or occlusions in major parts of a long vessel, natural tapering may create dilemma for optimal balloon sizing and optimal stent sizing during PCI [9].

Tapering is defined as the ratio of the area change to the vessel length [10]. Based on computed tomographic angiographic finding among 526 adult subjects from Asia by Zhang et al [11], it has been demonstrated that decremented ratio in left anterior descending, LCx and right coronary artery at origin and distal end were $9.7 \%, 7.7 \%$, and $5.1 \%$, respectively. These findings indicate that the dimensions naturally taper along the length of coronary arteries [11]. Morph stent comes in three sizes: $3.5-3,3-2.5$ and $2.75-2.25 \mathrm{~mm}$. A $3-2.5 \mathrm{~mm}$ Morph stent has proximal and distal diameter of 3 and $2.5 \mathrm{~mm}$, respectively when deployed at nominal pressure. Considering this, we opted for using one long tapered stent in our patient.

\section{Conflict of Interest}

None.

\section{References}

1. Bolte J, Neumann U, Pfafferott C, Vogt A, Engel HJ,
Mehmel HC, von Olshausen KE, et al. Incidence, management, and outcome of stent loss during intracoronary stenting. Am J Cardiol. 2001;88(5):565-567.

2. Brilakis ES, Best PJ, Elesber AA, Barsness GW, Lennon RJ, Holmes DR, Jr., Rihal CS, et al. Incidence, retrieval methods, and outcomes of stent loss during percutaneous coronary intervention: a large single-center experience. Catheter Cardiovasc Interv. 2005;66(3):333-340.

3. Ahmar W, Malaiapan Y, Meredith IT. Transradial retrieval of a dislodged stent from the left main coronary artery. J Invasive Cardiol. 2008;20(10):545-547.

4. Uyan C, Gunduz H, Arinc H, Akdemir R. Embolised stent into the circumflex coronary artery during percutaneous coronary intervention. Int Heart J. 2006;47(1):125-129.

5. Eggebrecht $\mathrm{H}$, Haude $\mathrm{M}$, von Birgelen $\mathrm{C}$, Oldenburg $\mathrm{O}$, Baumgart D, Herrmann J, Welge D, et al. Nonsurgical retrieval of embolized coronary stents. Catheter Cardiovasc Interv. 2000;51(4):432-440.

6. Holmes DR, Jr., Garratt KN, Popma J. Stent Complications. J Invasive Cardiol. 1998;10(7):385-395.

7. Raber L, Juni P, Loffel L, Wandel S, Cook S, Wenaweser $\mathrm{P}$, Togni $\mathrm{M}$, et al. Impact of stent overlap on angiographic and long-term clinical outcome in patients undergoing drug-eluting stent implantation. J Am Coll Cardiol. 2010;55(12):1178-1188.

8. Chan R, Lim R. Does stent size "Mismatch" predispose to restenosis? Heart, Lung Circ. 2010;19:S128.

9. Timmins LH, Meyer CA, Moreno MR, Moore JE, Jr. Mechanical modeling of stents deployed in tapered arteries. Ann Biomed Eng. 2008;36(12):2042-2050.

10. Van Geuns RJ, Awad K, IJsselmuiden A, Koch K. The role of self-expanding stents in patients with atypical coronary anatomy. Interventional Cardiology Review. 2014;9(1):11-16.

11. Zhang LR, Xu DS, Liu XC, Wu XS, Ying YN, Dong Z, Sun FW, et al. [Coronary artery lumen diameter and bifurcation angle derived from CT coronary angiographic image in healthy people]. Zhonghua Xin Xue Guan Bing Za Zhi. 2011;39(12):1117-1123. 